\title{
Entre a clausura e o hospital: atuação das Irmãs de Jesus na Santíssima Eucaristia na Santa Casa de Cachoeiro de Itapemirim
}

\author{
Between the cloister and the hospital: performance of the Sisters of Jesus \\ in the Holy Eucharist in the Holy House of Cachoeiro de Itapemirim
}

\author{
Luciene Carla Corrêa Francelino \\ Universidade Federal do Espírito Santo, Vitória, ES, Brasil.
}

\begin{abstract}
Resumo: O presente trabalho tem como objeto de análise a atuação das Irmãs de Jesus na Santíssima Eucaristia na Santa Casa de Misericórdia de Cachoeiro de Itapemirim - cidade localizada ao sul do estado do Espírito Santo - entre os anos de 1929 a 1950. Buscar-se-á discutir como o proceder das religiosas junto aos doentes e seus familiares, introduziu um modelo de cuidado fundamentado na caridade, acolhendo a todos que de alguma maneira dependiam da assistência do hospital. A pesquisa visa analisar como as mudanças causadas pela institucionalização da enfermagem chegaram ao município e de que maneira essas repercutiram no dia a dia da instituição. Pretende-se também compreender como as relações de poder no interior do hospital se alteraram na medida em que o conceito de cuidar, presente na prática cotidiana das Irmãs, vai sendo paulatinamente transformado pelo pressuposto do curar, praticado pela medicina.
\end{abstract}

Palavras-chave: Religiosas. Enfermagem. Santa Casa.

Abstract: The present work has as an object of analysis the performance of the Sisters of Jesus in the Holy Eucharist in the Holy House of Mercy of Cachoeiro de Itapemirim - city located to the south of the state of Espirito Santo - between the years of 1929 to 1950. to discuss how the religious of the sick and their families introduced a model of care based on charity, welcoming all who depended on hospital assistance. The research aims to analyze how the changes caused by the institutionalization of nursing came to the municipality and how they impacted on the day to day of the institution. It is also intended to understand how the power relations within the hospital have changed as the concept of caring present in the sisters' daily practice is gradually being transformed by the presupposition of healing, practiced by medicine.

Keywords: Religious. Nursing. Holy House.

\section{Introdução}

Na realização desse estudo foi utilizada como metodologia de pesquisa a História Oral, adotando uma abordagem qualitativa, a partir dos relatos obtidos junto às freiras que fazem parte da congregação em estudo. Em virtude do recorte temporal adotado (1929-1950) apenas uma

\footnotetext{
1 Mestre em História pela Universidade Federal do Espírito Santo (UFES). ORCID: orcid.org/ 0000-0001-9540-3600. Email: lucienecarla20@hotmail.com
} 
das quatro irmãs entrevistadas vivenciou o cotidiano da irmandade no período em que nossa pesquisa se insere. Ao adotar a História Oral como metodologia, não relegamos a segundo plano os diversos documentos e manuscritos que propiciaram a reconstituição desse importante período da história do município de Cachoeiro de Itapemirim. Outrossim, os relatos das religiosas colaboraram para fornecer respostas e elucidar questões, que ultrapassavam a objetividade dos documentos oficiais. Vidal (1990) destaca que ao tomarmos os relatos orais como verdades absolutas e incontestáveis podemos cometer diversos equívocos, por estarmos analisando os fatos a partir de uma ótica pessoal, isto posto, os depoimentos devem ser submetidos a uma análise minuciosa, de forma a contrapor as informações relatadas com outras fontes.

O trabalho com História Oral está diretamente relacionado às lembranças e memórias que os sujeitos envolvidos têm sobre determinada época e à situação vivenciada. Nessa perspectiva, o exercício de rememorar pode contribuir para que o entrevistado reflita sobre a sua vivência e construa novas concepções acerca do seu passado (BOSI, 1995).

\section{Origem da Santa Casa de Misericórdia}

Desde a antiguidade, a assistência aos desvalidos, pobres e doentes esteve associada à filantropia e caridade, seja através de ações implementadas pela Igreja e seus membros ou pelo trabalho de leigos. A palavra hospital é originária de hospitalidade e hotel, sendo que a era Cristã presenciou o surgimento de estabelecimentos religiosos que serviam como lugar de refúgio para necessitados e peregrinos, esses primeiros estabelecimentos eram mantidos por ordens religiosas, mas apesar de conter várias camas e até aparatos para a assistência aos desvalidos, esses locais podiam ser adaptados de acordo com a necessidade, não tendo, portanto, um caráter de permanência (BYNUM, 2011).

Em um contexto de epidemias, fome e guerras, surge a Misericórdia de Portugal, criada em 1498 sob o patrocínio de D. Leonor e confirmada por seu irmão, o rei D. Manuel I, tendo como principal objetivo proporcionar auxílio espiritual e material aos necessitados através da assistência institucionalizada aos doentes, tornando-se, portanto, um modelo para a fundação de diversos hospitais.

O modelo assistencial da Santa Casa chegou ao Brasil, assim como nas demais colônias portuguesas, a partir do século XVI, mas se por um lado é inegável o protagonismo institucional das Misericórdias, vale destacar que por trás da proteção régia havia uma nítida política de expansão dos estabelecimentos assistenciais. A rápida aceitação dos principais da terra escondia uma série de benefícios e privilégios destinados à irmandade, ou seja, a instalação de uma Misericórdia não era onerosa do ponto de vista financeiro à medida que seus custos eram pagos pelos setores mais abastados de cada localidade, por outro lado, os beneméritos que financiavam a instalação de tão importante instituição eram privilegiados do ponto de vista simbólico, tendo prestígio e notoriedade em suas localidades, favorecendo muitas vezes a inserção na vida política ou na "alta sociedade". A fundação das primeiras Santas Casas americanas acompanhou o surgimento de vilas e povoados, concedendo à instalação dessas novas instituições um duplo papel: em primeiro lugar confirmava a Misericórdia como uma das principais confrarias em tempos imperiais e, em segundo, a presença de uma irmandade 
como a Santa Casa conferia uma identidade - mesmo que lusa - às frágeis povoações que tanto careciam de elementos e instituições que as distinguisse e com as quais se identificassem. As Misericórdias mais expressivas, principalmente a partir do século XVIII, administravam além de serviços hospitalares, recolhimento de órfãos, boticas, roda dos enjeitados ${ }^{2}$, cemitérios, visita a cadeias, auxílio na alimentação e no livramento de presos pobres e distribuição de esmolas. Na América portuguesa, dois exemplos que mais se aproximaram desse tipo de atuação foram as Misericórdias do Rio de Janeiro e de Salvador (FRANCO, 2011).

\section{A Santa Casa de Misericórdia de Cachoeiro de Itapemirim}

Em Cachoeiro de Itapemirim a Santa Casa de Misericórdia foi fundada em 27 de janeiro de 1900 e inaugurada no dia 11 de fevereiro do presente ano, sendo que essa se originou da Associação Beneficência Cachoeirense, criada em 25 de dezembro de 1899 e, desde então, passou a prestar assistência aos indigentes e necessitados, contando com doações dos sócios e da comunidade local.

Vale destacar que essa Associação que deu origem a Santa Casa era composta majoritariamente por membros da maçonaria - dos 53 fundadores, 36 eram maçons - não tendo na época vinculação estreita com a Igreja Católica, como aconteceu com a maioria das confrarias responsáveis pela instalação de Santas Casas em território brasileiro. As demais Misericórdias fundadas por irmandades tinham como principal documento regulador de suas funções o Compromisso, sendo seus membros denominados de irmãos. Em contrapartida, a Misericórdia de Cachoeiro - certamente por influência da maçonaria - era regida por um Estatuto, sendo os membros chamados de sócios. Outro elemento de diferenciação é que em vez de um provedor, a Santa Casa de Cachoeiro possuía um presidente.

Em Cachoeiro, quando ainda não havia um nosocômio que atendesse a situações de emergência, foi realizada uma amputação na altura do antebraço direito de um homem residente em Muqui, vítima de explosão por dinamite. O mesmo foi operado pelo médico Raulino de Oliveira, tendo como assistentes um farmacêutico e um cirurgião dentista, o fato foi noticiado no jornal $O$ Cachoeirano no dia $1 .^{\circ}$ de junho de 1894 .

Uma das principais consequências do incentivo à caridade para os desvalidos, no campo da medicina, foi a disseminação de hospitais filantrópicos, maternidades e sanatórios patrocinados pela iniciativa privada. Em ata da $3^{\mathrm{a}}$ sessão ordinária da Câmara municipal de Cachoeiro de Itapemirim, em 10 de junho de 1896 foi decidido o seguinte:

[...] considerando que o $\S 1$ do artigo 36 da lei $n^{\circ} 6$ atribue ao governo municipal a competência de crear casa de caridade, inspencionar as existentes e fiscalizar o seu regime. Considerando que neste município particulares levantaram a ideia da creação de um hospital de caridade [...] considerando que a iniciativa

\footnotetext{
2 A roda dos expostos - também conhecida como roda dos enjeitados - era comum em muitas Misericórdias, geralmente ficavam junto ao muro das Santas Casas, sendo metade da roda para o interior e a outra metade para o exterior, desse modo a identidade da pessoa que ali abandonava a criança, ficava resguardada. Essas crianças eram geralmente filhos de mães solteiras, que eram ali deixadas na calada da noite para que fossem adotadas por famílias de posses ou abrigadas em algum orfanato da cidade. Para mais informações sobre o tema ver (MOULIN, 2011).
} 
individual pode ser mais proveitosa que a direta acção do governo: propomos que o governo municipal faça entrega a Associação ou Irmandade que se organizar do saldo existente e da casa adquirida, desde que a Associação ou Irmandade apresente os seus estatutos devidamente aprovados (ACTA DA 3. ${ }^{a}$ SESSÃO ORDINÁRIA DA CÂMARA MUNICIPAL DE CACHOEIRO DE ITAPEMIRIM, 10 de junho de 1896, p. 10).

Composta por médicos e membros da sociedade cachoeirense, o corpo diretivo da Associação Beneficência fundou um hospital destinado ao atendimento dos pobres e dos desvalidos que viviam no município, bem como em todo o sul do estado do Espírito Santo. No dia da inauguração, toda a população foi convidada a comparecer, sendo os comerciantes instruídos a fecharem os seus comércios a fim de prestigiar tão importante acontecimento.

No sábado, dia 27 do corrente, terá lugar a inauguração do hospital fundado às expensas da caridade pública [...] tendo a comissão recebido a delegação do povo e querendo dar o caráter festivo, a quem tem direito factos desta ordem, tem a honra de convidar às Exmas. famílias em participar e ao povo em geral para comparecerem na casa situada à Tijuca e já conhecida por Hospital, pela 1 hora da tarde, afim de proceder-se a necessária inauguração [...] roga-se aos Srs comerciantes o obsequio de fecharem suas portas do meio dia em diante, afim de que possão todos tomar parte na referida festa (JORNAL O CACHOEIRANO, 23 de janeiro de 1900).

Confirmando o seu caráter de assistência aos desvalidos, o Artigo segundo do Regimento da instituição determinava o seguinte:

São fins da Santa Casa de Misericórdia de Cachoeiro de Itapemirim: I - Manter assistência hospitalar às pessoas indigentes; II - Manter um consultório médico para pessoas pobres; III- Fornecer gratuitamente aos indigentes não internados no hospital os medicamentos receitados pelos médicos da Santa Casa; IV - Fazer gratuitamente o enterro dos indigentes que falecerem no hospital (REGIMENTO INTERNO DA SANTA CASA DE MISERICÓRDIA DE CACHOEIRO DE ITAPEMIRIM, 1945, p. 3).

Assim como ocorreu durante a colonização do Brasil, em que as Misericórdias possuíam um aspecto semiburocrático, atuando junto à população com medidas que na verdade eram de responsabilidade do poder público, a Santa Casa do sul do estado do Espírito Santo, recebia subvenção municipal e estadual, encarregando-se da assistência aos indigentes, pobres, desvalidos e doentes, conforme nota publicada no jornal O Cachoeirano em 23 de março de 1900, afirmando que a presidência do estado concederia mensalmente ao hospital a importância correspondente ao auxílio anual de 4:000\$ em conformidade com a Lei n. 339 de 16 de novembro de 1899. A assistência filantrópica sempre ocorreu ao longo da história da humanidade, o socorro aos pobres e desvalidos foi muitas vezes financiado por beneméritos, irmandades e associações de diversos modelos. 
Em Cachoeiro de Itapemirim a Santa Casa de Misericórdia recebia com frequência donativos em dinheiro e gêneros diversos, que eram utilizados para manter o hospital funcionando, com assistência aos necessitados. O que geralmente ocorria, como o noticiado no dia 29 de abril de 1930, é que eram divulgados o nome dos beneméritos e a quantia doada em dinheiro, geralmente elencada em ordem decrescente. Demonstraremos um esboço das doações que eram noticiadas na imprensa (Tabela 1):

Tabela 1 - Doações noticiadas na imprensa

\begin{tabular}{|c|c|}
\hline Producto do Festival de Estudantes & $500 \$ 000$ \\
\hline José Antonio Ribeiro & $550 \$ 000$ \\
\hline Vivacqua Vieira \& Co. & $110 \$ 000$ \\
\hline [...] Dr. Aristides Campos & $50 \$ 000$ \\
\hline Dr. Vicente Burian & $50 \$ 000$ \\
\hline [...] Anacleto Ramos & $50 \$ 000$ \\
\hline Antonio Martins & $30 \$ 000$ \\
\hline Dr. Bricio Mesquita & $25 \$ 000$ \\
\hline$[\ldots]$ H. Urso & $20 \$ 000$ \\
\hline [...] Dr. Cleveland Paraiso & $20 \$ 000$ \\
\hline Gil Moreira & $10 \$ 000$ \\
\hline Quintiliano de Azevedo & $10 \$ 000$ \\
\hline$[\ldots] 73$ donativos menores de $10 \$ 000$ & $247 \$ 200$ \\
\hline $\begin{array}{l}\text { Total arrecadado: } \\
\text { (Tres contos, trezentos e sessenta e sete mil e duzentos réis) }\end{array}$ & Rs. 3:367\$200 \\
\hline
\end{tabular}

Fonte: Jornal Correio do Sul (1930). ${ }^{3}$

As doações de gêneros alimentícios seguiam o mesmo modelo, nome do benfeitor, item e quantidade doados:

Antonio Sequim \& Filhos, 1 lata de balas, 2 sacos de assucar; Josino Cordeiro, 10 kilos de macarrão; Luiz Perim, 10 litros de fubá, 5 kilos de café; Altamiro Robertino, 1 kilo de macarrão; Brahim Depes, 4 kilos de macarrão, 2 latas de marmelada; José Felix Tannure, 5 kilos de feijão [...] Carlos Torres, 2 sabonetes [...] (JORNAL CORREIO DO SUL, 29 de abril de 1930, p. 2).

Listagem publicada no Jornal Correio do Sul, em 29 abr. 1930, p. 2. 
Os benfeitores que doavam gêneros ou quantias em dinheiro para a Santa Casa de Cachoeiro tinham os seus nomes divulgados em periódicos de circulação no município. Além de ser uma forma de reconhecimento público, a notícia de que aquelas pessoas eram colaboradoras de obra social tão nobre, servia, muitas vezes, como trampolim político ou meio de conseguir inserção na "grande sociedade" do município.

De acordo com o estatuto e o regimento interno da Santa Casa de Cachoeiro, uma das principais finalidades da instituição era prestar assistência hospitalar aos indigentes, além de manter um consultório médico para atendimento daqueles que não podiam custear um tratamento de saúde. Em entrevista gravada no ano de $1990^{4}$, o médico Dalton Penedo - que ingressou na instituição na década de 1930 - informou que as pessoas que utilizavam os serviços do hospital nesse período eram pertencentes às camadas menos favorecidas da população, indivíduos vítimas de acidentes ou em tratamento de moléstias graves. As pessoas mais abastadas tinham o médico de família, que realizava atendimento domiciliar. Havia, ainda, um sem número de práticos e curandeiros que realizavam a chamada medicina alternativa, ou seja, havia certa resistência por parte da coletividade em procurar o hospital. Mas esse cenário começou a mudar a partir da chegada das freiras que passaram a atuar na Santa Casa em 1929. Outro fator importante para alterar esse quadro foi a divulgação dos avanços da medicina e das novas práticas profiláticas nos jornais do município, através de folhetins e sessões que tinham a finalidade de informar sobre os sintomas de diversas doenças, bem como formas de prevenção e tratamento, sempre utilizando uma linguagem prática e acessível a todos.

\section{Religiosas no interior dos hospitais: as irmãs enfermeiras}

O trabalho junto aos doentes foi uma das várias formas de atuação filantrópicas que ao longo dos séculos aliou-se à história da enfermagem. Várias ordens religiosas foram criadas voltadas para a assistência aos desvalidos, esses ideais de amor ao próximo, marcaram o desenvolvimento da enfermagem, estabelecendo um modelo comportamental para o cuidado com os enfermos. Na primeira era cristã - até o ano 500 - uma das primeiras ordens de mulheres que trabalhavam junto aos desvalidos foram as diaconisas e as viúvas, mais tarde integraram-se as virgens, as presbiterianas, as canônicas e as irmãs de caridade (DONAHUE, 1993).

A companhia das Irmãs de Caridade foi fundada em 1633, na França, pelo padre Vicente de Paula e pela religiosa Luísa de Marillac. O momento em que essa ordem foi criada coincide com o período em que a miséria e as doenças causadas por longos anos de guerras estavam arruinando o país. A companhia tinha o compromisso de alimentar os pobres, realizar trabalhos de assistência espiritual nos lares e cuidar dos doentes nos hospitais, além de reorganizar tais espaços, implementando princípios higiênicos através da individualização dos leitos. De acordo com (CASTRO, 1936) a companhia das Irmãs de Caridade foi fundada para que houvesse mulheres que servissem apenas aos necessitados, por tempo integral, sem outras ocupações

\footnotetext{
4 Entrevista realizada em 5 de dezembro de 1990, em comemoração aos 90 anos da Santa Casa de Cachoeiro, presente no acervo do Centro de Estudos da Santa Casa (Fita Cassete ${ }^{\circ}{ }^{\circ} 7$ ).
} 
relacionadas à vida pessoal, como casamento e a família. O treinamento dessas jovens devia ser de poucas palavras, havendo momentos destinados para o exercício da catequese e os cuidados domésticos. Os comandos eram dados através de olhares e gestos. O ensino da enfermagem era ministrado pela superiora às demais Irmãs, através de cartas explicativas ou por meio da prática cotidiana umas com as outras. Não havia ainda um manual escrito ou organização técnica, mas a implementação das ações relacionadas ao cuidado com os enfermos se aproximava do que viria futuramente a ser as "técnicas de enfermagem" ou palmas, evocando a moral e a obediência.

Florence Nightingale é considerada fundadora da enfermagem moderna, nasceu em 12 de maio de 1820 em Florença, em uma família abastada. Estudou diversos idiomas, além de religião, filosofia e matemática, era extremamente religiosa e desde muito cedo apresentava o desejo de ajudar aos pobres e necessitados. Participou como voluntária na Guerra da Crimeia em 1854, quando juntamente com 38 mulheres (irmãs católicas e anglicanas) organizou um hospital com 4 mil soldados internos, conseguindo diminuir a mortalidade, que era de $40 \%$, para $2 \%$. Recebeu um prêmio do governo inglês em virtude desse trabalho e fundou a primeira escola de Enfermagem no Hospital St. Thomas em Londres no ano de 1860. Conheceu o trabalho realizado pelas Irmãs de Caridade de São Vicente de Paulo em Paris, no Hôtel-dieu ${ }^{5}$, acompanhando de perto o trabalho administrativo e assistencial que estas realizavam, tendo acesso às regras que norteavam o trabalho das religiosas, o modo como cuidavam dos doentes, aprofundando seus estudos através de anotações, gráficos e listas das atividades desenvolvidas. Em outro momento, retornou ao hospital, permanecendo ali por um mês, vestindo o hábito das irmãs, para sentir o carisma - chamado vocacional para a lida com os necessitados - o convívio com as religiosas no interior do hospital, certamente influenciou a maneira como Nightingale estruturou o seu modelo de Enfermagem (PADILHA; MANCIA, 2005).

No século XIX as Irmãs de Caridade passaram a atuar na administração das Santas Casas em várias partes do Brasil, data de 1852 a vinda das Irmãs de São Vicente de Paula para assumirem os serviços de enfermagem, administrativo e religioso da Santa Casa do Rio de Janeiro, estando subordinadas de forma direta ao provedor (PADILHA, 1998).

No final do século XIX as freiras eram responsáveis por inúmeros trabalhos essenciais para a sociedade, principalmente nos campos da assistência social, da educação e da saúde. Com exceção das mulheres pobres, que sempre exerceram diversas funções fora do lar para garantir a subsistência da família, as religiosas foram pioneiras no exercício de uma determinada profissão, em um tempo em que grande parte das mulheres exercia apenas as funções de mãe e de dona de casa. A vida religiosa não pode ser, portanto, considerada como marcada apenas por submissão e passividade, ao contrário, essas mulheres eram muitas vezes administradoras de colégios, hospitais, orfanatos e de inúmeras obras sociais. Eram elas que determinavam os horários e as regras a serem cumpridas, organizavam a rotina de várias pessoas e resinificavam a condição feminina, em uma sociedade patriarcal e machista (NUNES, 1997).

5 O nome significa Casa de Deus, é considerado o mais antigo hospital de Paris, fundado no ano 650. Era administrado por leigos, mas o atendimento aos doentes era realizado pelas Irmãs Agostinianas, considerada a mais antiga ordem de Irmãs enfermeiras. Atuavam na administração do hospital, cuidado dos doentes e serviços religiosos (PADILHA, 1999, p. 444-445). 
Nesses locais, que eram ao mesmo tempo de clausura e liberdade, o princípio fundamental era a separação do mundo. O comportamento das religiosas que viviam a clausura em conventos ou fora deles devia ser distinto do que se observava na sociedade de um modo geral. A vestimenta, a obediência absoluta, a exigência do silêncio durante as refeições, acabavam criando um mundo à parte, esses locais em que as irmãs atuavam eram de trabalho e de residência, nos quais as mesmas possuíam o controle rigoroso dos membros e da organização do espaço.

Em 1916 ocorreu uma reunião da diretoria da Santa Casa sob a direção do então presidente Felinto Elysio Martins, na qual o mesmo declarou que a finalidade daquela sessão era deliberar sobre a conveniência de encarregar o serviço de enfermeiras do hospital às Irmãs de Caridade. A proposta foi colocada em votação e aprovada por unanimidade, mas não havia congregação, nem religiosas atuando em Cachoeiro, tampouco nos arredores, por isso apesar de aprovada a proposta não se efetivou.

A congregação das Irmãs de Jesus na Santíssima Eucaristia, foi fundada em Cachoeiro no ano de 1927 por madre Gertrudes de São José. No mesmo ano a religiosa inaugurou um colégio, com a finalidade de escolarizar moças da região. Atento ao trabalho das religiosas junto à comunidade do município, o então presidente da Santa Casa, Mário Rezende, escreveu uma carta à madre pedindo a atuação das religiosas junto aos enfermos do hospital, atendendo ao pedido feito, a superiora designou algumas freiras da irmandade para atuarem na Santa Casa de Cachoeiro.

\section{Entre o cuidar e o curar: as religiosas na Santa Casa de Misericórdia}

É nesse contexto de profundas transformações em relação ao discurso médico e ao tratamento de moléstias diversas, que as Irmãs de Jesus na Santíssima Eucaristia passam a administrar a Santa Casa de Cachoeiro de Itapemirim. Esse período foi marcado pela incidência de doenças graves que dizimaram um grande contingente populacional na região, entre essas enfermidades pode-se citar a lepra, a tuberculose, a febre amarela e a febre tifoide.

A hipótese defendida no presente trabalho é que as religiosas cuidavam dos doentes internados na instituição, mas esse cuidado rompia as fronteiras do corpo e alcançava os limites da alma, visto que se preocupavam com o conforto espiritual dos convalescentes e de seus familiares, favorecendo a cura ou minimizando o sofrimento e possibilitando uma melhoria na qualidade de vida daqueles que eram atendidos no hospital. No dia 7 de maio de 1929 foi publicado uma nota sobre a entrega da direção de todos os serviços internos da Santa Casa aos cuidados das Irmãs de Jesus na Eucaristia, sendo a Superintendência Geral dos Serviços à encargo da Madre Gertrudes de São José. Após dois dias, o periódico publicou o contrato de serviço firmado entre a congregação e o hospital. Desse contrato, que tem nove cláusulas, se destacam:

$1^{\mathrm{a}}$. A Irmã Gertrudes de São José, diretora do Colégio Sagrado Coração de Jesus, também designada primeira contratante, contrata com a Santa Casa de Misericórdia de Cachoeiro de Itapemirim, também designada contratante ou simplesmente Santa Casa, representada por seu presidente Mário Resende e devidamente auto- 
rizada por Assembleia Geral, a direção interna de todos os serviços, sem despesa alguma para a primeira contratante e sob as condições seguintes:

$2^{\text {a }}$. A primeira contratante obriga-se a superintender todo o serviço interno das dependências da Santa Casa, inspecionando-os diariamente sob força maior e zelando para sua economia, limpeza, asseio, ordem e moralidade. Conforme dispõe o regulamento interno;

(...) $7^{\mathrm{a}}$. A segunda contratante obriga-se a dar às Irmãs uma alimentação boa, sadia (...) bem como no caso de doenças de qualquer delas, dar-lhes também além dos necessários medicamentos, a respectiva assistência médica e, verificando algum falecimento, serão por conta da Santa Casa todas as despesas de transporte e enterro.

A residência das irmãs era nas dependências da Santa Casa. Elas assumiram a responsabilidade da chefia de diversos setores, como: farmácia, centro cirúrgico, enfermagem, maternidade, lavanderia, além do serviço de assistência espiritual aos enfermos e seus familiares. De acordo com a irmã Aurora Côgo ${ }^{6}$, havia no hospital uma diretoria "leiga", formada por membros da sociedade local e a diretoria interna, na qual as irmãs atuavam e a que cabia supervisionar todos os setores do hospital.

Ao contrário da diretoria "leiga", que tinha horário fixo de trabalho, as irmãs permaneciam no hospital - por residir nas dependências do mesmo - por isso em qualquer emergência elas acionavam os médicos e demais membros da diretoria. Os pacientes se identificavam muito com as freiras e relatavam suas angústias, temores e até se queixavam caso entendessem que estavam sendo vítimas de maus-tratos ou descaso por parte da equipe médica. Nesse sentido, o papel destas era fundamental, pois se o médico quisesse continuar atuando na instituição precisava de certa forma do aval das religiosas, se houvesse malsinações por parte dos enfermos relacionadas à sua prática, as religiosas podiam denunciá-lo, ocasionando a demissão do mesmo.

Com a finalidade de traçarmos um perfil das Irmãs que atuaram na Santa Casa, resgatamos um pouco da história por meio de entrevistas com quatro freiras da irmandade, das quais apenas uma vivenciou o cotidiano do hospital no período em estudo, de 1929 a 1950. As demais ingressaram na congregação alguns anos mais tarde e se dispuseram a recuperar a história da mesma para a constituição deste estudo.

Começaremos o resgate histórico da irmandade - no âmbito que convém à nossa pesquisa com a religiosa Vitalina Verônica7, que nasceu em 1931, no interior de Muniz Freire - sul do estado do Espírito Santo - a mesma ingressou na congregação com apenas 14 anos. A religiosa relatou que ela e os demais irmãos acordavam cedo e acompanhavam o pai no trabalho na roça. Na época,

\footnotetext{
6 Irmã Aurora Côgo foi superior a da congregação durante oito anos, atualmente é missionária em Angola, onde aplica junto aos desassistidos os conhecimentos de psicoterapia corporal e elaboração de remédios naturais. O relato contido neste trabalho foi coletado nas dependências do Colégio Jesus Cristo Rei, no dia 10 de julho de 2017, em Cachoeiro de Itapemirim. Na época a religiosa estava de férias no Brasil e participando de um congresso promovido pela irmandade.

7 Vitalina Verônica Boniziolli, ao ingressar na congregação, adotou o nome religioso de Maria Pia Vicentina. Atualmente, com 87 anos, é a única freira que vivenciou o período que compreende nossa pesquisa, 1929 a 1950. O relato da religiosa foi obtido no dia 3 de abril de 2018 na Casa-mãe da congregação, nas dependências do Colégio Jesus Cristo Rei.
} 
eram sete filhos, a mais nova nasceu quando Vitalina já estava na congregação. Costumava andar cerca de três horas para chegar até a igreja. Durante uma missa, que contava com a presença de freiras, ficou muito impressionada com a vestimenta e a postura das mesmas e decidiu, então, que entraria para a vida religiosa. Ao término da celebração, conversou com o bispo e este entrou em contato com a madre, após alguns meses ingressou na irmandade. Quando entrou na Santa Casa, em 1947, estava com 17 anos, não tinha nenhuma experiência na área da saúde, mas se tornou aprendiz e atuou na Enfermaria Masculina e no Pronto-Socorro. Segundo a freira, na época em que trabalhou na Santa Casa - 1947 a 1951 - havia pouquíssimos funcionários no hospital, por isso, frequentemente, as Irmãs acordavam de madrugada para atender os doentes que clamavam por auxílio, ou casos graves que davam entrada no nosocômio. Os profissionais de "enfermagem" possuíam apenas conhecimentos práticos, adquiridos através de treinamento em serviço. Na época, além das Irmãs, havia dois "enfermeiros” que atuavam no pronto-socorro e na sala de operação. Irmã Vitalina destacou que as freiras costumavam prestar auxílio espiritual aos pacientes, principalmente aos casos mais graves, além das orações, sempre que possível chamavam um padre para dar a extrema-unção, para que o enfermo não morresse sem esse sacramento.

Outra freira que colaborou com nossa pesquisa foi Eurides Florentino ${ }^{8}$ que, atualmente, está aposentada e vive em uma casa - também chamada de comunidade - da congregação, em Vila Velha - município do Espírito Santo pertencente à região metropolitana - Eurides nasceu em 1936, no interior de Colatina - cidade localizada ao norte do Espírito Santo. A mesma relatou que quando criança já sentia o desejo de ingressar na vida eclesiástica. Se tornou membro da congregação das Irmãs de Jesus em 1955, passando a atuar na Santa Casa de Cachoeiro como aprendiz em 1958. Essa primeira experiência na Santa Casa foi curta, visto que atuou em hospitais da região de Itaperuna - norte do Rio de Janeiro - junto com outras Irmãs. Em 1970, fez um curso de enfermagem na cidade de Vitória, capital do Espírito Santo, que tinha duração de dois anos e foi ministrado por professoras que se formaram na renomada Escola de Enfermagem Anna Nery. No ano de 1972, retornou para a Santa Casa de Cachoeiro, atuando nos setores de Pediatria, Banco de Sangue e Maternidade. Segundo a Irmã Eurides, as freiras residiam no hospital e sua rotina iniciava as 4 h3o com orações que duravam até as 6h30. Por volta das 7h elas tomavam o café da manhã e, em seguida, cada uma se dirigia para o seu setor. Por volta das $12 \mathrm{~h}$ era o almoço - sem intervalo para descanso - e retomavam para o trabalho que, geralmente, ia até às 19h. Entretanto, as freiras podiam ser acionadas a qualquer hora da noite para atenderem a alguma emergência que porventura surgisse. A religiosa relatou que "trabalhavam pela roupa e comida”, pois não havia salário, e que elas jamais tocavam em dinheiro, mas, em contrapartida, todo e qualquer tratamento de saúde que necessitavam era feito pelo hospital, sem necessidade de pagamento.

\footnotetext{
8 O relato da religiosa foi obtido através de conversa com a autora no dia 25 de julho de 2017, em uma das casas da congregação, situada em Vila Velha. No local funciona o Centro de formação Martina Toloni e uma clínica de tratamento natural, onde as Irmãs oferecem à comunidade serviços de podologia, massagem, remédios caseiros e outras terapias alternativas. A casa abriga Irmãs que estão aposentadas, aquelas que necessitam de tratamento de saúde, além das que atuam em obras sociais no município. Em relação ao fato da freira não saber que recebia salário, essa se demonstrou surpresa quando informei a respeito do salário coletivo, demonstrando curiosidade em relação ao valor do salário nos dias atuais.
} 
Ouvimos também a Irmã Ivone Serrão Cezar ${ }^{9}$ que nasceu em 1942, no distrito de Itajara, interior de Itaperuna - estado do Rio de Janeiro. Vivia em uma fazenda de propriedade da família, junto com os pais e dez irmãos. Ivone relatou que sempre gostou das “coisas religiosas", apesar da missa ser ministrada em latim. Aos 15 anos começou a participar da reunião das Filhas de Maria, na qual as meninas oravam e entoavam hinos. A diretora da reunião que era ex-aluna de freiras, do colégio Salesiano, incentivou Ivone a ingressar na vida religiosa, pois afirmava que a menina tinha "jeito de freira". A mesma relatou que a ideia de viver para Deus a encantou e passou a pensar continuamente nessa possibilidade. Ingressou na congregação das Irmãs de Jesus em 1961, com 19 anos de idade, em um período que segundo a religiosa havia muitas vocações. Passou a trabalhar na Santa Casa de Cachoeiro em 1973 como “ajudante de enfermagem”. Nesse período aprendeu com as profissionais mais experientes a aferir pressão arterial, aplicar injeções, medir temperatura e realizar as demais tarefas próprias das técnicas de enfermagem. Na época em que trabalhou no hospital havia seis freiras atuando na instituição, dirigindo alguns setores como a Farmácia ou atuando na área de Enfermagem. Segundo a religiosa, os enfermeiros-chefes tinham curso superior e suas auxiliares procuravam fazer o curso técnico de enfermagem. ${ }^{10}$ De acordo com a freira, o trabalho nas enfermarias era exaustivo demais, "quase desumano", tanto que no último ano em que atuou na instituição - 1978 - pediu para ser transferida para outro setor.

Conversamos também com Irmã Otíliaa ${ }^{11}$, que nasceu no interior de Minas Gerais, em 1933, e, como as demais Irmãs, informou que sempre quis ingressar em uma irmandade religiosa. Entrou para a congregação em 1960, aos 20 anos de idade e começou a atuar na Santa Casa por volta do ano de 1961. Trabalhou coordenando a limpeza, a cozinha, costurando roupas, além de prestar auxílio aos profissionais do Pronto-Socorro. Segundo a religiosa, nesse período já havia vários profissionais com formação na área de enfermagem e que com o passar dos anos o número aumentou de forma significativa, tanto que as freiras podiam cuidar de setores administrativos ao invés de atuarem diretamente junto aos doentes. A mesma informou que, a partir de então, passou a se dedicar mais ao trabalho espiritual dos pacientes e de seus familiares, muitas vezes relatando as necessidades destes junto aos seus superiores. Irmã Otília também alegou que não recebia salário para o cumprimento das tarefas que realizava.

\footnotetext{
9 Conversamos com Irmã Ivone em 22 de março de 2018, nas dependências da casa em que ela vive, junto com três religiosas, localizada no bairro BNH, no município de Cachoeiro de Itapemirim. O local funciona como centro de formação para a primeira etapa da vida religiosa, denominada de postulantado. A residência das Irmãs também é denominada de comunidade inserida em meios populares, visto que estas auxiliam na paróquia local.

10 A religiosa relatou que no período de 1975-1976, ela e outra funcionária leiga fizeram o curso de auxiliar de enfermagem promovido pela Loja Maçônica de Cachoeiro.

${ }_{11}$ Irmã Maria Joana Otília fez os relatos no dia 22 de maio de 2017, nos corredores da Santa Casa de Misericórdia de Cachoeiro, onde ainda atua prestando auxílio espiritual aos pacientes. A mesma reside nas dependências do colégio Jesus Cristo Rei, junto com as Irmãs que dirigem o educandário e tem uma jornada de trabalho diária no hospital, recebendo um salário mensal para isso. A conversa com a religiosa foi interrompida várias vezes por funcionários, visitantes e parentes de pacientes que chegavam para abraçá-la, cumprimentá-la e pedir a sua benção. A freira fez questão de mencionar que a conversa não poderia alongar-se por muito tempo, pois estava em serviço. Em relação ao trabalho que executa atualmente, informou que, além de visitar e orar pelos pacientes no leito, intercede pelos mesmos junto aos médicos e dirigentes do hospital para agilizar os procedimentos ou solucionar questões relacionadas às queixas, reclamações ou solicitações. Notamos que a freira é muito estimada pelos pacientes, familiares e funcionários da instituição, nossa conversa foi interrompida diversas vezes por pessoas que vinham abraçá-la, pedir a benção ou simplesmente cumprimentá-la.
} 
Como foi demonstrado através do contrato firmado entre a Santa Casa e a superiora da congregação, as religiosas recebiam um salário mensal, mas ele era coletivo e servia para a manutenção das demais obras implementadas pela irmandade, como escolas e orfanatos. O que acontece é que, provavelmente, algumas religiosas desconheciam que possuíam um vínculo empregatício com o hospital, recebendo salários como todo trabalhador que desempenhasse trabalho formal junto à uma instituição.

Uma freira que colaborou muito para a compreensão da dinâmica da congregação em estudo foi Aurora Côgo, que, embora não tenha trabalhado na Santa Casa, é uma das responsáveis pela preservação da história das religiosas de Jesus na Santíssima Eucaristia. Aurora nasceu no interior de Muniz Freire' em 1942, e, como as demais Irmãs citadas nesta pesquisa, nutriu desde muito cedo o desejo de ingressar a vida religiosa, principalmente depois que seu irmão entrou no seminário com a finalidade de se tornar padre. Ingressou na congregação em 1957, com 15 anos de idade. Entre os vários relatos que fez, destacou que quando entrou para a congregação era semialfabetizada e toda a formação que possui é congregacional. Ela se formou em pedagogia e fez especializações em metodologia de aprendizagem, psicoterapia corporal e teologia pastoral. Enfatizou que nunca atuou na Santa Casa, mas sempre acompanhou de perto as Irmãs que ali trabalhavam, acalentando o sonho de um dia ser enfermeira, mas como a congregação necessitava de um número maior de professoras, passou a atuar nesta área.

Durante a pesquisa, nos questionamos acerca da contradição de informações acerca das freiras não receberem um salário para o exercício de suas funções junto à Santa Casa de Cachoeiro, conforme relatos das Irmãs Otília e Eurides. E a existência de um contrato de trabalho firmado entre o hospital e a superiora da irmandade que demonstrava exatamente o contrário, na medida em que estabelecia os vencimentos individuais de cada freira. ${ }^{12}$ Irmã Aurora esclareceu que o salário das Irmãs era coletivo, ou seja, era entregue à superiora para ser aplicado em obras sociais mantidas pela congregação. E utilizado para suprir as modestas necessidades das religiosas.

Os relatos aqui apresentados tiveram o objetivo de auxiliar na compreensão acerca de quem eram e como viviam as mulheres que dedicaram a vida a auxiliar e socorrer o próximo no interior da Santa Casa de Cachoeiro. Na impossibilidade de ouvir todas as freiras que atuaram no período em estudo, entre 1929 e 1950, optamos por resgatar parte do cotidiano delas por meio do olhar e da vivência de outras que trabalharam na mesma instituição em um período posterior. Uma análise superficial poderia caracterizar os relatos e as memórias das freiras como uma construção coletiva, responsável por uma visão unilateral do recôndito da irmandade. Ao ouvir as narrativas delas, em alguns momentos tivemos a impressão de se

\footnotetext{
${ }_{12}$ As freiras Eurides e Otília afirmaram que não recebiam salário para atuar na Santa Casa de Cachoeiro. Além disso, há dois livros de escritores cachoeirenses que reforçam as afirmações das religiosas. Moulin (2010) assevera que as religiosas atuavam em todos os setores do nosocômio, exceto o Financeiro, e que não recebiam salários, por isso eram chamadas de voluntárias (MOULIN, 2011, p. 38). Enquanto Moreira (2017) destaca que o trabalho da irmandade junto aos enfermos se estabelecia em troca de alimentação e domicílio, uma vez que a residência das freiras era nas dependências da Santa Casa (MOREIRA, 2017, p. 32). Entretanto, conforme demonstramos através do contrato de trabalho entre a Santa Casa e a superiora da congregação, as freiras recebiam salário. Durante nossa pesquisa tais informações trouxeram inquietações por serem contraditórias. Através de seus relatos, a freira Aurora Côgo esclareceu que o salário recebido pelas Irmãs era coletivo, sendo o mesmo aplicado nas demais obras sociais da irmandade e utilizado de acordo com as necessidades da congregação.
} 
tratar de uma história idealizada a partir da convivência diária e do "ufanismo" existente em torno da história de vida da fundadora da irmandade. Isto porque os relatos que ouvimos demonstraram muitas semelhanças, sobretudo em relação ao chamado espiritual das religiosas, que, segundo as mesmas, ocorreu desde os mais tenros anos de vida.

Entretanto, conforme mencionamos anteriormente a maioria das jovens que ingressavam na congregação eram oriundas da zona rural, membros de famílias numerosas. Eram incorporadas à vida eclesiástica no período da adolescência e, a partir de então, treinadas a incorporar o que Grossi (1990) denominou de "jeito de freira”. Além disso, recebiam um modelo de formação pautada em princípios religiosos e morais rígidos e viviam durante anos com membros da mesma irmandade. Nessa perspectiva, entendemos que diante de uma vivência com tantas semelhanças, as memórias pessoais e comunitárias se misturaram, gerando uma memória coletiva. Fato semelhante acontece quando recorremos às lembranças de nossos irmãos ou amigos para recordarmos determinado evento que vivenciamos juntos, muitas vezes construímos uma memória acerca de um acontecimento, tomando emprestado as lembranças de outros. Contudo, é importante mencionar que as narrativas das Irmãs e sua visão de mundo foram essenciais para a constituição deste estudo, sem elas a compreensão acerca da dinâmica da congregação se tornaria fragmentada e circunscrita.

As religiosas da congregação atuaram na direção da Santa Casa de Cachoeiro entre os anos de 1929 a 1950. De acordo com o Regimento Interno em vigor no ano de 1945, as freiras eram encarregadas de todo o serviço administrativo da instituição, como podemos averiguar a seguir:

Art. 116 - O SERVIÇO ADMINISTRATIVO, se relacionando com tudo o que diz respeito a administração interna do Hospital, é dirigido pelo presidente, que terá como auxiliares diretos, religiosas da Irmandade que para isso tiver contrato com a Santa Casa (REGIMENTO INTERNO DA SANTA CASA DE MISERICÓRDIA DE CACHOEIRO DE ITAPEMIRIM, 1945, p. 23).

Até a primeira metade do século passado as mulheres tinham muito pudor de se consultarem e de realizarem seus partos com médicos, o mais usual é que partejassem no conforto de seus lares sob os cuidados de uma parteira. Mas a partir da inserção das Irmãs no quadro de funcionários da Santa Casa ocorreu uma mudança significativa nesse sentido.

Irmã Celina que ingressou na congregação com 24 anos, passou a atuar na Santa Casa como parteira no ano de 1935, nas horas vagas costurava roupas para bebês, cintas e camisolas para as mães pobres, geralmente chamadas de indigentes. A religiosa trabalhou no hospital por 52 anos, calcula-se que tenha realizado cerca de 10 mil partos (MOULIN, 2011).

Havia preocupação por parte da madre com a espiritualidade das freiras que trabalhavam na Santa Casa. Em carta de 10 de agosto de 1939 a superiora alerta que as freiras se lembrem do capítulo $9^{\circ}$ das Constituições - principal documento regulador da congregação - que determinava a proibição das Irmãs de terem amizades com qualquer pessoa, fosse religiosa ou secular: 
Nenhuma Irmã poderá ter correspondência com qualquer que seja sem licença de sua superiora e nem amizades particulares com pessoas religiosas, mesmo Confessores, Diretores, etc. Como também é proibido fazer e receber presentes, entreter-se com conversas fiadas com qualquer secular, isto é, médicos, enfermeiros, empregados etc., mesmo com sacerdotes fora do confessionário (CARTAS DE MADRE GERTRUDES DE SÃO JOSÉ, 10 de agosto de 1939, p. 117).

Na mesma carta madre Gertrudes destaca a importância da obediência à determinação da Saúde Pública, que ordenou a todas as pessoas que tratavam com doentes a vestirem-se de branco. A superiora asseverou que "em todos os hospitais onde havia atuação de membros da irmandade, as religiosas deveriam usar um avental inteiro com mangas compridas e véu branco".

Podemos observar que as mudanças no pressuposto do cuidar para o curar começam a chegar no município a partir do final da década de 1930 alterando de certa forma a rotina do hospital e o modo de atuação das freiras junto aos doentes. Houve resistência por parte das religiosas em acatar a nova vestimenta, conforme consta em trechos da carta escrita pela madre em o9 de outubro de 1939, na qual a mesma alertou às Irmãs que senão adequassem a indumentária conforme o recomendado, sofreriam punições:

Cumprindo as leis e exigências da Saúde Pública, ordenei como vós sabeis, que todas as Irmãs dos diversos Hospitais pusessem avental branco inteiro com mangas compridas e véu de morim cambraia mas há Diretoras que, ao invés de serem as primeiras a obedecer às ordens de sua Superiora Geral, recusam-se a cumprir o que ela manda dando assim mau exemplo às suas subalternas. Para evitar escândalos dessa natureza, proibirei a renovação dos votos às Irmãs que antes da data fixada para a renovação, não estiverem todas vestidas de branco (CARTAS DE MADRE GERTRUDES DE SÃO JOSÉ, 9 de out. 1939, p. 121).

As Irmãs que atuavam na Santa Casa de Cachoeiro passaram a buscar capacitações através de cursos de enfermagem, como forma de adequação aos novos rumos da saúde no País. No dia 8 de março de 1946, madre Gertrudes escreveu às irmãs Olívia e Celestina sobre a importância de ambas fazerem o curso de enfermagem superior na renomada escola Ana Nery no Rio de Janeiro, para obtenção de certificado. A superiora destacou na correspondência que “o estudo e a prática adquirida na escola possuía muito valor nos hospitais”. irmã Olívia foi a pioneira, fazendo inclusive especialização em São Paulo, ao regressar para Cachoeiro passou a ministrar cursos de "auxiliar de enfermagem" com emissão de certificados. Antes disso o que havia era a aprendizagem na prática, adquirida no dia a dia da instituição.

As cartas escritas pela superiora eram lidas em todas as congregações em que as religiosas da irmandade atuavam, como forma de alertar, corrigir, informar e encorajar as demais. Em 2 de maio de 1937 a madre escreveu uma Carta Circular endereçada as "queridas filhas da Santa Casa de Misericórdia”, na qual elogiava o trabalho das religiosas e destacava que havia perseguições e dissabores na jornada das freiras. 
Apesar de não ser objetiva em relação ao que significam essas perseguições, a hipótese que aqui defendemos é de que havia conflitos no interior do nosocômio, em virtude das mudanças que ocorriam na implementação do novo modelo de saúde coletiva que se institucionalizava.

Os anos de 1950 e 1960 foram marcados por intensa efervescência na sociedade brasileira, em virtude do desenvolvimento industrial e urbano, além do decisivo atrelamento da economia nacional ao capital estrangeiro. $\mathrm{Na}$ área cultural as transformações foram extremamente significativas visto que os meios de comunicação passaram a disseminar novos valores, inclusive o uso da pílula anticoncepcional que revolucionou os costumes. Essas transformações afetaram também a atuação das freiras, para além dos muros dos conventos, ou seja, enquanto predominou na sociedade uma ideia sacralizada de mundo, as religiosas exerciam sem nenhuma ressalva, funções para as quais não estavam tecnicamente habilitadas, atuavam como professoras, enfermeiras e assistentes sociais. Mas a modernidade passou a exigir habilitação específica para o exercício de diversas profissões, o que dificultou a permanência das freiras nas diferentes obras em que atuavam, mesmo assim a participação das mesmas na área de assistência social continuou sendo exercida. A resposta das congregações a essa nova realidade foi o incentivo à profissionalização das religiosas (NUNES, 1997).

A partir da década de 1950 as irmãs deixaram de administrar a Santa Casa, permanecendo nas dependências da instituição apenas como funcionárias do nosocômio. Segundo relatos da religiosa Aurora Côgo esse momento de transição está relacionado a mudança pela qual a medicina estava passando, pela ampliação da atuação do hospital e a complexidade que este passa a ter. Segundo a mesma, se transformando, muitas vezes, em "fonte de lucro".

A saída das irmãs da administração da Santa Casa estava relacionada a transformações sociais que afetaram a dinâmica do hospital. A demanda por atendimento aumentou significativamente, o que acarretou a expansão do quadro de funcionários, além disso havia a determinação dos órgãos de saúde pública para que o atendimento aos enfermos fosse realizado por profissionais formados nas escolas de enfermagem regulamentadas. Nesse período, passaram a atuar na instituição enfermeiras e enfermeiros com formação técnica, seus valores e vivências acabavam indo de encontro aos ideais religiosos das Irmãs, que eram proibidas de manter amizades com seculares. Em Carta endereçada à Irmã Elisa, diretora das freiras na Santa Casa, a superiora pede notícias detalhadas acerca das freiras que atuavam no hospital e alerta sobre a compostura religiosa que deveriam ter ao se relacionarem com seculares:

Eu queria saber notícias detalhadas sobre as Irmãs se cumprem bem o seu emprego, se são sérias com os médicos e empregados, se há harmonia e carinho entre elas, se guardam a compostura religiosa com os seculares ou se há alguma amizade particular enfim minha filha que não sobrevenha alguma novidade desagradável como a que já houve aí e em outras casas [...] desejaria também saber se a nova administração trata bem as Irmãs, as considera e respeita, como também se o Capelão cumpre o seu dever (CARTA DE MADRE GERTRUDES DE SÃO JOSÉ, 20 de agosto de 1951). 


\section{Conclusão}

As relações entre hospitais e irmãs enfermeiras começam a se modificar a partir da década de 1940 com a tendência nacional de inserir nos espaços hospitalares enfermeiras e enfermeiros leigos, formados em escolas especializadas e reconhecidas pelos órgãos de saúde pública do país. Favorecendo o surgimento de um novo modelo de enfermagem, no qual as freiras não mais se adequavam. Destarte, é inquestionável a dedicação e o desvelo do trabalho destas junto aos enfermos, bem como sua contribuição para a enfermagem moderna.

As novas determinações dos órgãos de saúde pública, a inserção de profissionais laicos nas enfermarias da Santa Casa de Cachoeiro e as diferenças entre o universo secular e o religioso, contribuíram para que as Irmãs de Jesus deixassem de administrar o nosocômio e de atuar diretamente junto aos doentes como enfermeiras. Religiosas e funcionários da instituição, apesar de conviverem no mesmo espaço físico, viviam em “universos diferentes”. As irmãs enfermeiras eram, antes de tudo, freiras, essa era a sua real profissão e ideal de vida. A partir do momento em que as atribuições referentes à atuação no hospital entraram em conflito com seu chamado espiritual, não hesitaram em se retirar da administração interna do nosocômio e, gradativamente, foram migrando para outras áreas de atuação, sem, contudo, interromper seu compromisso missionário.

\section{Referências}

ABREU, Laurinda. O papel das Misericórdias dos lugares além-mar na formação do império português. História, Ciências, Saúde, Rio de Janeiro, v. VIII (3): 591-611, set./dez. 2001. https:// doi.org/10.1590/s0104-59702001000400005

ANCHIETA, José de. Cartas, Informações, Fragmentos Históricos e Sermões do Padre José de Anchieta (1554-1594). Rio de Janeiro: Civilização Brasileira S.A, 1933.

BOSI, Ecléa. Memória e Sociedade: lembrança de velhos. São Paulo: Companhia das Letras, 1995. BYNUM, William. História da medicina. Porto Alegre: L\&PM Pocket, 2011.

CALMON, Pedro. História do Brasil (Séc. XVI). Rio de Janeiro: Livraria José Olympio Editora, 1971. https://doi.org/10.1017/s0003161500065585

FOUCAULT, Michel. Vigiar e punir. Petrópolis (RJ): Vozes, 1987.

FRANCO, Renato. Pobreza e caridade leiga: as Santas Casas de Misericórdia na América Portuguesa. 2011. Tese (doutorado). Universidade de São Paulo. USP, São Paulo, 2011. https:// doi.org/10.11606/t.8.2011.tde-25052012-133000

GEREMEK, Bronislaw. A piedade e a forca: história da miséria e da caridade na Europa. Lisboa: Terramar, 1986.

GROSSI, Miriam Pillar. Jeito de freira: estudo antropológico sobre a vocação religiosa feminina. Caderno de Pesquisa São Paulo, n. 73,, p. 48-58, maio 1990.

Jornal Correio do Sul, Ano I, junho de 1928 a junho de 1929.

Jornal O Cachoeirano, 1900 e 1901. Biblioteca nacional - hemeroteca digital.

Livro de Impressões - Relatos de Visitantes da Santa Casa de Misericórdia de Cachoeiro de Itapemirim - 1929 a 1949. https://doi.org/10.5327/z2447-211520191900014 
Livros de Atas de 1900 a 1951 da Santa Casa de Misericórdia de Cachoeiro de Itapemirim. https://doi.org/10.5327/z2447-211520191900014

MADRE GERTRUDES DE SÃO JOSÉ. Cartas. Congregação das irmãs de Jesus na Eucaristia (maio de 1937 a junho de 1962). Belo Horizonte: Editora São Vicente, 1981.

MOULIN, Ariette. Santa Casa de Misericórdia de Cachoeiro de Itapemirim, 1900 - 2010. Cachoeiro de Itapemirim: Gracal, 2011. https://doi.org/10.17655/9788567211534

NUNES, Maria José Rosado. Freiras no Brasil. In: DEL PRIORE, Mary (org). História das mulheres no Brasil. São Paulo: Contexto, 1997. https://doi.org/10.4000/clio.210

PADILHA, Maria Itayra Coelho de Souza. A mística do silêncio: a enfermagem na Santa Casa de Misericórdia do Rio de Janeiro no século XIX. Pelotas (RS): Universitária/UFPel, 1998. https://doi.org/10.1590/s0034-71671998000200015

PADILHA, Maria Itayra Coelho de Souza; MANCIA, Joel. Rolim. Florence Nigthingale e as irmãs de caridade: revisitando a história. Revista Brasileira de Enfermagem, Brasília, v. 58, n. 6, p. 723-726, 2005. https://doi.org/10.1590/s0034-71672005000600018

PADILHA, Maria. Itayra. Coelho de Souza. As Representações da História da Enfermagem na prática cotidiana atual. Revista Brasileira de Enfermagem, Brasília, DF, v. 52, n. 3, p. 443- 454, jul./set. 1999. https://doi.org/10.1590/s0034-71671999000300014

SÁ, Isabel dos Guimarães; PAIVA, José Pedro. Introdução. In: PAIVA, José Pedro (coord.). A fundação das Misericórdias: o reinado de D. Manuel I. Lisboa: Centro de Estudos de História Religiosa, 2004. v. 3, p. 7-26.

STEPAN, Nancy. Gênese e evolução da ciência brasileira: Oswaldo Cruz e a política de investigação científica e médica. Rio de Janeiro: Artenova, 1976.

VIDAL, Diana Gonçalves. De Heródoto ao gravador: histórias da História Oral. Resgate Revista de Interdisciplinar de Cultura do Centro de Memória - UNICAMP, Campinas, n. 1, 77-82, 1990. https://doi.org/10.20396/resgate.v16i17.8645665

WOOD - Russel, A.J. R. Fidalgos e filantropos: a Santa Casa da Misericórdia da Bahia (1550 1755). Brasília: Editora da UnB, 1981. https://doi.org/10.1007/978-1-349-00172-9_4

Recebido em: 6/1/2019.

Aprovado em: 22/8/2019.

\section{Luciene Carla Corrêa Francelino}

Endereço postal:

Rua Edgar Beraldo n. 20, Bairro: Baiminas

Cachoeiro de Itapemirim/Espírito Santo - Brasil

CEP: 29305.411 